\title{
Heavy Ion Fusion (HIF) Impulse Injector Design, Construction, and Checkout
}

\author{
M. J. Wilson \\ D. Goerz \\ R. Speer \\ R. Moal
}

May 4, 1998

This is an informal report intended primarily for internal or limited external distribution. The opinions and conclusions stated are those of the author and may or may not be those of the Laboratory.

Work performed under the auspices of the U.S. Department of Energy by the Lawrence Livermore National Laboratory under Contract W-7405-Eng-48. 


\section{DISCLAIMER}

This document was prepared as an account of work sponsored by an agency of the United States Government. Neither the United States Government nor the University of California nor any of their employees, makes any warranty, express or implied, or assumes any legal liability or responsibility for the accuracy, completeness, or usefulness of any information, apparatus, product, or process disclosed, or represents that its use would not infringe privately owned rights. Reference herein to any specific commercial product, process, or service by trade name, trademark, manufacturer, or otherwise, does not necessarily constitute or imply its endorsement, recommendation, or favoring by the United States Government or the University of California. The views and opinions of authors expressed herein do not necessarily state or reflect those of the United States Government or the University of California, and shall not be used for advertising or product endorsement purposes.

This report has been reproduced directly from the best available copy.

Available to $\mathrm{DOE}$ and $\mathrm{DOE}$ contractors from the Office of Scientific and Technical Information P.O. Box 62, Oak Ridge, TN 37831

Prices available from (423) 576-8401

Available to the public from the National Technical Information Service

U.S. Department of Commerce 5285 Port Royal Rd, Springfield, VA 22161 


\section{Table of Contents}

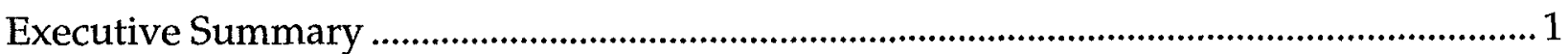

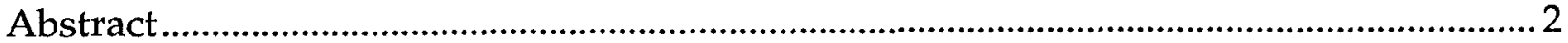

1.0 Introduction

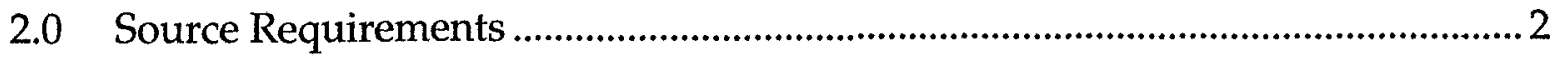

3.0 Selected Approach.................................................................................................

4.0 Impulser Layout ................................................................................................. 5

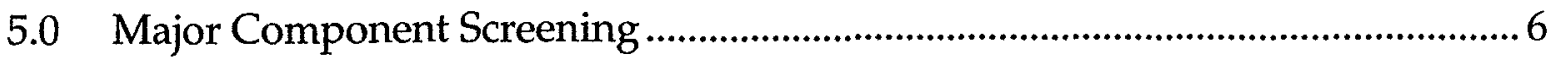

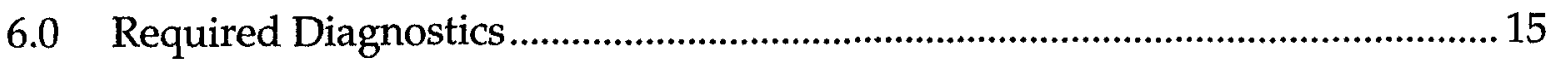

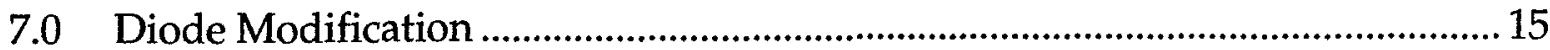

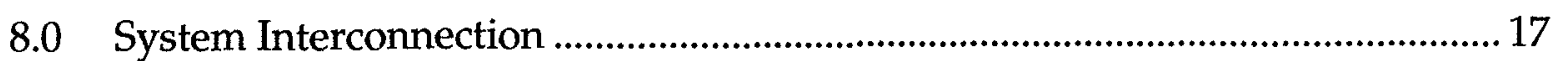

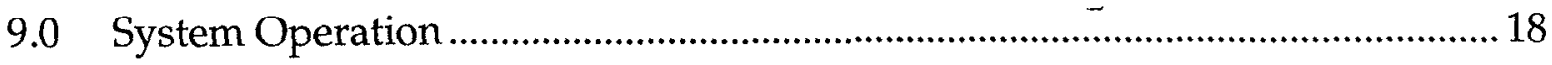

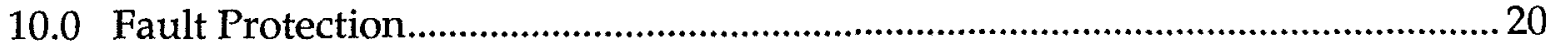

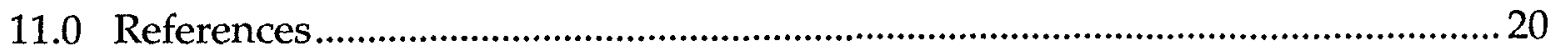




\section{Executive Summary}

The heavy ion fusion (HIF) project provides one of two basic concepts for the next generation of accelerators. The HIF concept involves a circular accelerator instead of a linear accelerator approach. Both concepts have common problems, issues, and concerns. The circular approach has obvious financial advantages compared to the linear approach. The main advantage of the circular approach is the ability to use accelerator stages more than once during beam acceleration. As a result, the additional required controls become one of the more significant technical challenges to the project. Before these issues can be addressed, it is of primary importance that the injected beam is of adequate quality. Particle beam accelerators use various system topologies to obtain desired energies. A typical accelerator will have three basic subsystems. The first is sometimes referred to as the source or injector, the second involves multiple stages of accelerator cavities, and the third might be considered the target area. Each stage of beam development interacts with the previous and subsequent stage. During the acceleration phase for example, pre-existing beam characteristics are amplified and may cause beam instabilities. Instabilities manifest themselves as oscillations. The initial beam profile is highly dependent on the injector characteristics. The following effort addresses the design, construction, and checkout of a retrofit to the existing accelerator diode and its associated driver. The results of this design have provided an elegant solution for beam development. 


\begin{abstract}
The following report describes the design, construction, and checkout of a high-voltage (HV) impulser built for the heavy ion fusion (HIF) project. The purpose of this impulser is to provide an adjustable diode voltage source of sufficient quality and level to allow the optimization of beam transport and accelerator sections of HIF. An elegant, low-impedance, high-energy storage capacitor circuit has been selected for this application. A retrofit to the diode region has been included to provide additional beam stability and a controlled rise time. The critical part of this circuit that is common to all candidates is the impedance matching component. The following report provides a description of the implemented circuit, the basic circuit variables for wave shaping, component screening techniques, resulting operating parameters, diode modifications, operating considerations, and fault protection.
\end{abstract}

\title{
1.0 Introduction
}

The purpose of this effort is to provide a regulated impulse to a thermionic diode. The diode provides the ion beam foundation for HIF. The quality of the impulse regulation directly effects the initial beam profile and the required complexity of the acceleration section. Poor beam quality prematurely compromises the level of acceleration to the beam instability level.

Several approaches used to meet the impulse requirements have shown modest success at limited levels. (A review and assessment of previous approaches goes beyond the scope of this report.) A low-impedance source was selected as the workhorse for the impulser. The topology of the impulser was provided along with environmental considerations. The results of screening major components provides increased confidence in the impulser reliability. The methodology to qualify the impulser parameters is presented in this report. The general requirement to control the diode electrical characteristics provided the insight to high beam quality. Modification to the interconnections of the diode interface was included to help improve system operation and reliability. An operational guideline concludes this work, but does not replace or supersede internally required Operational Safety Procedures (OSPs) or Facility Safety Procedures (FSPs).

\subsection{Source Requirements}

A fast-track engineering approach to provide an impulser to HIF followed the initial exchange of desired requirements. A review of the system requirements and a proposed design quickly followed with the principal HIF personnel. A summary of the requirements is provided in Table 2.0-1. The accelerated effort was required to effectively use specialized resources and adapt to other project schedules. 
Table 2.0-1 Initial engineering design requirements used to develop the proper impulse generator for the HIF project.

\begin{tabular}{|c|c|c|c|c|}
\hline Parameter & Units & \multicolumn{3}{|c|}{ Value } \\
\hline $\begin{array}{l}\text { shape } \\
\text { \& polarity }\end{array}$ & $\begin{array}{c}\text { square wave } \\
\text { positive }\end{array}$ & minimum & nominal & maximum \\
\hline $\begin{array}{l}\text { Flat Top Voltage } \\
\text { (FTV) }\end{array}$ & kV & 75 & 80 & 120 \\
\hline pulse width & $\mu \mathrm{s}$ & 1 & 5 & 6 \\
\hline TILT CONTROL & & \multicolumn{3}{|c|}{$?$} \\
\hline $\begin{array}{l}\text { rise time }(10-90 \%) \\
\text { @ } 80 \mathrm{kV}\end{array}$ & $\begin{array}{c}n s \\
(\min / \max 5 \%)\end{array}$ & 310 & 326 & 342 \\
\hline $\begin{array}{l}\text { rise time }(10-90 \%) \\
\text { @ } 100 \mathrm{kV}\end{array}$ & $\begin{array}{c}\text { ns } \\
(\min / \max 5 \%)\end{array}$ & 277 & 292 & 307 \\
\hline $\begin{array}{l}\text { fall time }(10-90 \%) \\
@ 80 \mathrm{kV}\end{array}$ & $\begin{array}{c}\text { ns } \\
(\min / \max 5 \%) \\
\end{array}$ & 310 & 326 & 342 \\
\hline $\begin{array}{l}\text { fall time }(10-90 \%) \\
\text { @ } 100 \mathrm{kV}\end{array}$ & $\begin{array}{c}\mathrm{ns} \\
(\min / \max 5 \%)\end{array}$ & 277 & $292^{-}$ & 307 \\
\hline overshoot & $\%$ of nominal FTV & $?$ & 1 & 2 \\
\hline ripple & $\%$ of nominal FTV & & & 0.1 \\
\hline $\begin{array}{l}\text { Flatness (droop) } \\
\text { over } 5 \mu \mathrm{s}\end{array}$ & $\%$ nominal FTV & & 0.5 & \\
\hline repeatability & pulse to pulse & \multicolumn{3}{|c|}{$?^{*}$} \\
\hline jitter (pulse to pulse) & ns & & 20 & 50 \\
\hline repetition rate & $\mathrm{Hz}$ & & 1 & $? ?$ \\
\hline
\end{tabular}

* Glassman HVPS has a sperified $0.05 \%$ stability over 8 hours

\subsection{Selected Approach}

The selected approach used to meet the project needs was based on available resources within the Defense Science Engineering Division/Electromagnetic \& Diagnostic Group (DSED/EMD). This group provides advance source development and diagnostic experience to a large client base both internal and external to LLNL. Other commitments required that the solution be timely and basically "in hand." A system-level look at the diode or load requirements exposed an inherent problem with mismatched impedances. The basic solution to resolve the diode parameter requirement is applicable to any selected impulse technology. The issues then became the available hardware and scheduling concerns. The following circuit shown in Figure 3.0-1 represents the first order approach to provide a stiff source as the impulser.

The basic circuit, as illustrated in Figure 3.0-1, consists of a $100 \mathrm{nF} / 200 \mathrm{kV}$ capacitor (C1), a series UV-illuminated gas switch (S1), and impedance matching resistor (R3), a variable augmenting diode capacitor (C2), a robust crowbar switch (S2), and a crowbar resistor (R2). The 
interconnections are defined by inductance (L1, L2, and L3). The rise time is adjusted to the desired profile with $\mathrm{L} 3$ and $\mathrm{C} 2$. The overshoot is controlled by the proper selection of R3. The impedance of the interconnection L3 to the diode and capacitance C2 defines the value of R3.

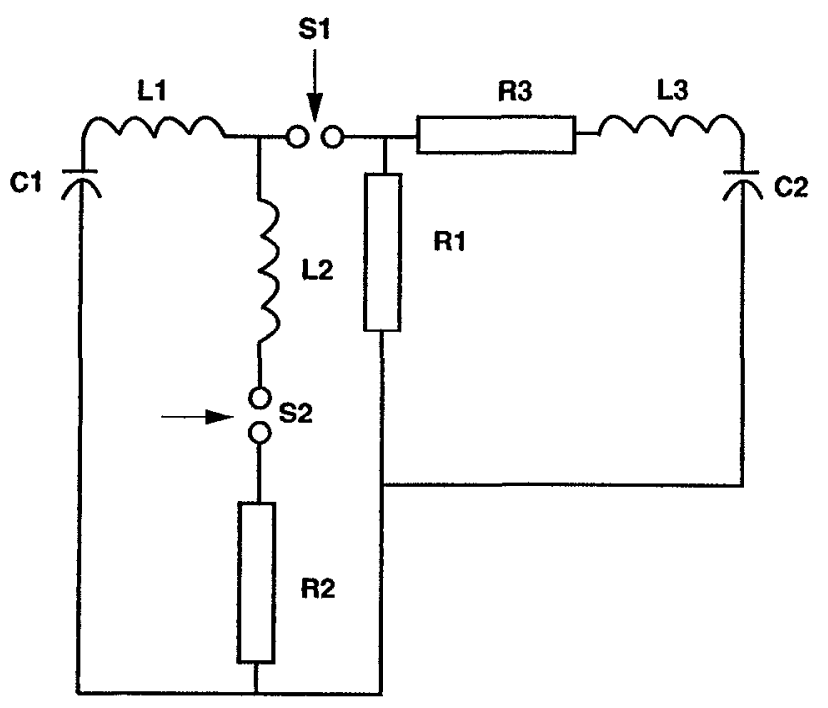

Figure 3.0-1 The above figure illustrates the basic circuit used as the HIF diode impulser.

The following parameters represent the initial parameters used to demonstrate the level of anticipated circuit performance. Critical to the proper operation of this type of circuit is the selection of R3. The parameter that is controlled by this decoupling component is the overshoot. The optimum value for this component is given by the following relationship:

$$
R 3=2.3 \times \sqrt{\frac{L 3}{C 2}}
$$

In addition:

$$
\begin{aligned}
& \mathrm{C} 1=100 \mathrm{nF} \\
& \mathrm{C} 2=10 \mathrm{nF} \\
& \mathrm{L} 1=200 \mathrm{nH} \\
& \mathrm{L} 2=200 \mathrm{nH} \\
& \mathrm{L} 3=200 \mathrm{nH} \\
& \mathrm{R} 1=100 \mathrm{k} \Omega \\
& \mathrm{R} 2=3 \Omega \\
& \mathrm{R} 3=10.5 \Omega
\end{aligned}
$$

S1-Provides for the initiation of the impulse into the load.

S2-Provides for a triggered crowbar before diode closure. The final circuit incorporates a fault detector to ensure that if diode closure does occur, then the crowbar will activate and discharge the system in approximately $500 \mathrm{~ns}$. 
Consider the test configuration with an initial charge voltage of $100 \mathrm{kV}$, and a selected C2 of $10 \mathrm{nF}$. The impulser with a selected width of $5 \mu$ s will have 500 joules (J) stored in $C 1$ and transfer $50 \mathrm{~J}$ into $\mathrm{C} 2$. The pulse width is only given as a reference and needed to view any power issues. A diode intrinsic capacitance of $100 \mathrm{pF}$ will store $0.5 \mathrm{~J}$ at $100 \mathrm{kV}$. C2 becomes the main energy storage component in the diode region. The energy stored in $\mathrm{C} 2$ discharges through $\mathrm{R} 2$ and $\mathrm{R} 3$ at a rate defined by L3 and C2. Consider that L3 with a length of one-meter has an inductance of approximately $1.3 \mu \mathrm{H}$. The resulting frequency is defined by the following relationship:

$$
F=\frac{1}{2 \pi \sqrt{L C}}
$$

The resulting frequency is $1.4 \mathrm{Mhz}$ with a period of $720 \mathrm{~ns}$. The contributing factor of L3 to the discharging impedance is given by $\omega \mathrm{L}$, which for this case is $14 \Omega$. The dynamic impedance of $\mathrm{L} 3$ and $\mathrm{C} 2$ given by the square root of the ratio of $\mathrm{L} 3$ to $\mathrm{C} 2$ is $11.4 \Omega$. The combined R2 an R3 value is nominally $28 \Omega$. The resulting $Q$ of the circuit is slightly greater than 2 . The effect of this to the discharge characteristics of the diode will be similar to those of the impulse charging and limit the undershoot during the crowbar phase. The result is a fall time on the diode approximately equal to the rise time.

This approach provided an elegant solution to the impulser requirements in a timely fashion. The selected circuit components provided a robust design that should provide a reasonable project evaluation tool. The next generation of impulsers required beyond the immediate project needs should take these issues into consideration as an integrated approach to an engineered injection diode. (This is perceived as a programmatic long-term issue and beyond the scope of this effort.)

\subsection{Impulser Layout}

The initial intent of the impulser layout was to reduce the overall package of the unit and relax the need for an oil environment. The typical packaging of choice for EMD is pressurized gases. Figure 4.0-1 illustrates a compact topology to fit into a reasonable environmental chamber. Shown are the energy storage capacitors, series and crowbar switches, an internal voltage probe on the series switch output, triggering inputs, and the first set of crowbar resistors. A compromise use of oil was required to accommodate the HV-bushing/filament vacuum interface. This insulator is not rated for pressure greater than an atmosphere. Fit-up and checkout of the impulser was done in a 55-gallon barrel providing a reasonable compact topology. The final configuration is shown in Figure 4.0-2. The impulser is shown to the side of the vacuum interface and above the parallel isolation transformers. 


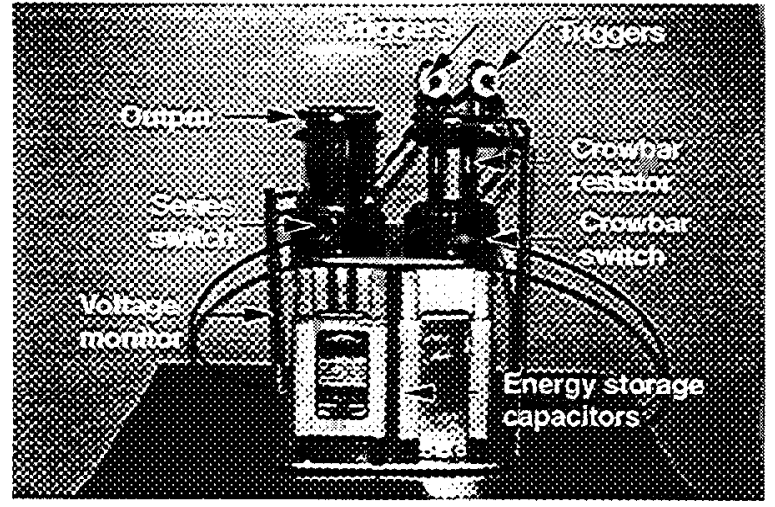

Figure 4.0-1 The above photo illustrates a compact package technique typically imploded by EMD. The design of this package allows operation to $50 \mathrm{kV}$ in one atmosphere of air and higher levels in SF6 or oil environments.

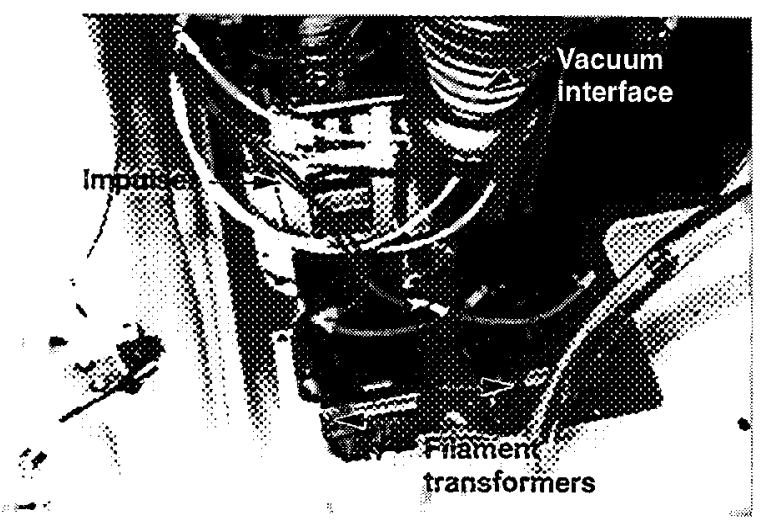

Figure 4.0-2 A top view of the impulser inside the oil tank shows two series isolation transformers located below vacuum high-voltage insulator.

Awareness on the part of DSED/EMD of the electromagnetic compatibility (EMC) issues associated with impulse techniques provided an added value to the design. A common interconnection panel and a low-inductance return plane provided some of the controls used to minimize these effects. Figure 4.0-3 (shown below with temporary removal of the tank cover) provides a view of the interface panel and a 12-inch ground return.

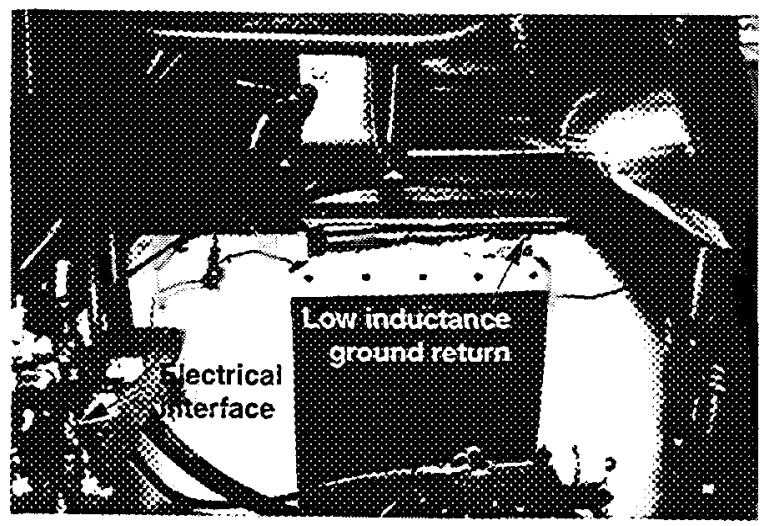

Figure 4.0-3 The above photo shows low-inductance ground plane and the electrical interconnecting panel. These are some of the initial controls to minimize electromagnetic compatibility (EMC) issues.

\subsection{Major Component Screening}

Three major components in the impulser were screened to improve system reliability. These components were the $40-\mathrm{nF} / 100 \mathrm{kV}$ energy storage capacitor, the $3-\mathrm{nF} / 40 \mathrm{kV}$ pulse shaping capacitors, and the $100 \mathrm{kV}$ crowbar gas switch. The following section describes the screening process and related information. 


\subsection{Screening 40 nF/100 kV Capacitors}

Ten $40-\mathrm{nF} / 100 \mathrm{kV}$ capacitors provided the primary energy stage for this impulser. To increase the confidence and reliability of this section, 12 units were screened. During the fit-up process, two of these units failed. (Spare capacitors are available as replacement parts in the future if needed.) The $120 \mathrm{kV}$ upper level of desired operation provided a design safety margin of 2 for the main storage section $\mathrm{C} 1$, as previously defined. The initial configuration required that the capacitor be qualified for a vacuum environment. The first task was to remove any surface oil. The units were then screened in a vacuum chamber by evacuating each unit to -28 inches of $\mathrm{Hg}$. Qualified candidates were then installed in six atmospheres of SF6 and elevated to $100 \mathrm{kV}$ at a nominal rate of $50 \mathrm{kV} / \mathrm{sec}$. Twelve exposures to this level were made on each component while measuring the current. The screening criteria of this step was to ensure that no unit exhibited an abnormal amount of leakage current after being charged to $100 \mathrm{kV}$ during a two-second stress level. Figures 5.1-1 and 5.1-2 show a representative charge voltage and current of a sample component, respectively. The selected value for $\mathrm{C} 1$ consisted of an array of two $40-\mathrm{nF} / 100 \mathrm{kV}$ capacitors connected in series. As mentioned above, this provided a nominal design safety margin of two for these components.

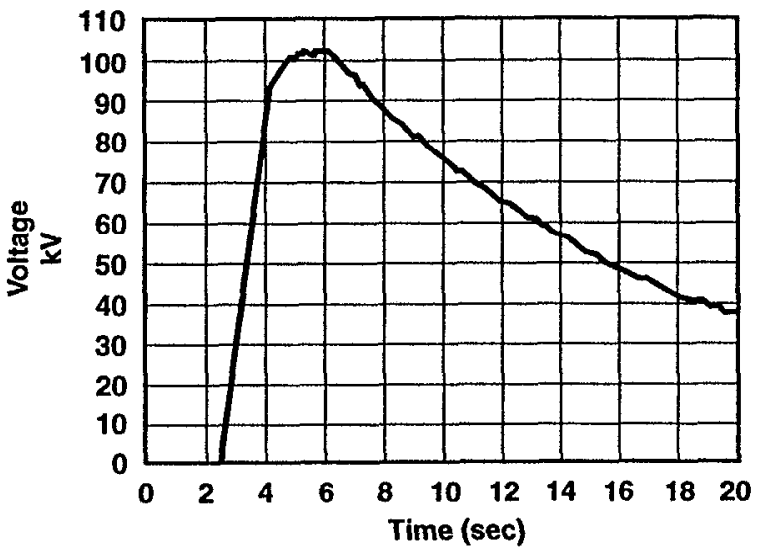

Figure 5.1-1 The above wave shape provides a typical view of the applied voltage to a $40-\mathrm{nF} / 100 \mathrm{kV}$ oil filled capacitor. Illustrated is a rate of rise of $50 \mathrm{kV} / \mathrm{sec}$ to $100 \mathrm{kV}$. The vertical scale is $10 \mathrm{kV} /$ division. The voltage as shown is held at $100 \mathrm{kV}$ for approximately 2 seconds and then discharged through the power supply at an exponential rate. Each unit is subjected to this level of stress 12 times to screen out marginal units.

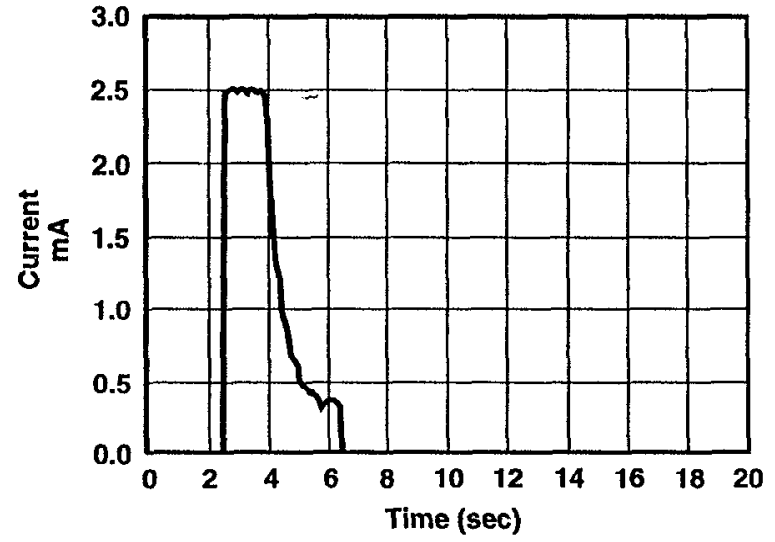

Figure 5.1-2 The above wave shape provides a typical view of the applied current to a $40 \mathrm{nF} / 100 \mathrm{kV}$ oil filled capacitor during the voltage screening process. The critical issue in this case is to assure similar leakage currents at the fully stressed level of $100 \mathrm{kV}$. The vertical scale for this measurement is $0.5 \mathrm{~mA} /$ division and the horizontal scale is $\mathbf{2}$ seddivision. The current level of $2.5 \mathrm{~mA}$ indicates the measured limit of the power supply used for this screening process. A typical leakage current measured on the selected components is $0.3 \mathrm{~mA}$ as indicated at the horizontal value of 6 secs. The level of leakage is primarily component related. 
As indicated in Figure 5.1-2, the nominal leakage of the selected capacitors was $0.3 \mathrm{~mA}$ at $100 \mathrm{kV}$. As a result of this excessive leakage current, 25 watts of power was dissipated inside the capacitor. A process to reduce these internal losses has been developed by LLNL [1]. Ten capacitors of the current available units had a combined leakage of $3 \mathrm{~mA}$. This indicates that a power supply minimum requirement for operation at $100 \mathrm{kV}$ would have an impedance of $33 \mathrm{M} \Omega$ and a minimum power requirement of $300 \mathrm{~W}$. A $2 \mathrm{~kW} / 125 \mathrm{kV}$ Glassman power supply has been procured to support the impulser. The combined trigger circuit bias strings of $50-\mathrm{M} \Omega$ total gave additional power supply loading during the charge phase of operation. The equivalent loading to the power supply became nominally $20 \mathrm{M} \Omega$, and at $100 \mathrm{kV}$ consumes $500 \mathrm{~W}$ of power per shot. Added to the system-operating requirement of $500 \mathrm{~J}$ per shot, the maximum repetition rate of the circuit became $2 \mathrm{~Hz}$ for the given power supply. Open circuit measurements showed that the measured voltages and currents on the screened components were representative of the device under test (DUT) and not the test circuit. The representative test fixture wave shapes are provided in Figures 5.1-3 and 5.1-4 for the voltage and current, respectively. The measured current in the test fixture is 10,000 less than that measured across the DUT. As a result, all the current measured in the screening process was considered to be in the screened component.

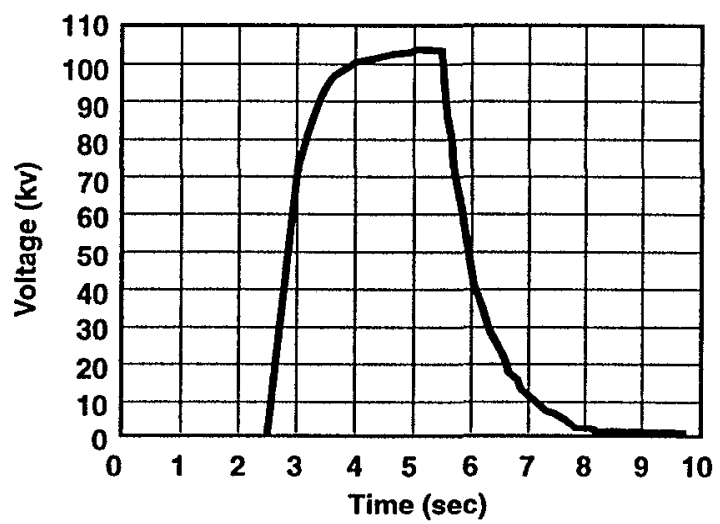

Figure 5.1-3 The resulting open circuit voltage into the test fixture is indicated in the above wave shape. The vertical scale in voltage is $10 \mathrm{kV} /$ division and the horizontal scale in time is $1 \mathrm{sec} /$ division. The nominal test voltage is shown to be $100 \mathrm{kV}$ having a flat stress level of two seconds.

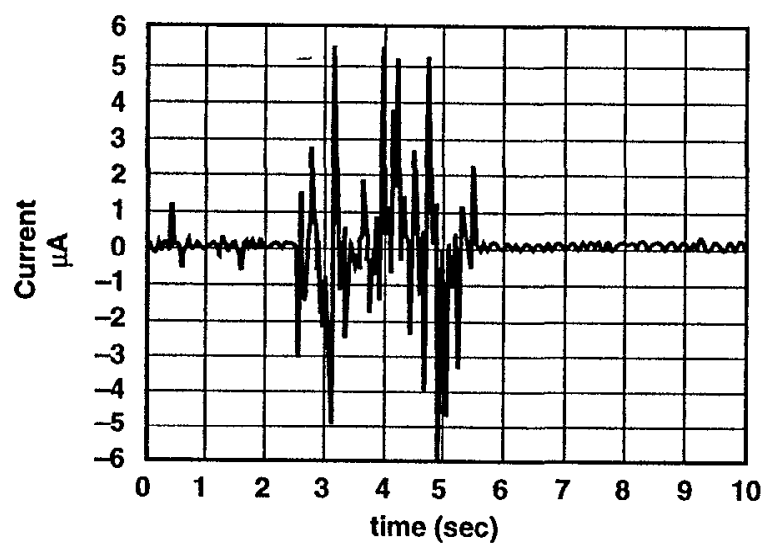

Figure 5.1-4 The power supply current associated with the baseline voltage shown in figure 5.1-3 is shown above. The measured current is represented by a vertical current displacement shown in $1 \mu \mathrm{A} /$ division and a horizontal time in 1 sec/divisions. During the stressing period of the applied voltage, the power supply open circuit is less than $6 \mu \mathrm{A}$ peak.

A review of the selected capacitor information provided from Maxwell Laboratories, Inc. indicated that the units are rated for a $1 \mathrm{~Hz}$ operation. This specification is at full rated voltage and voltage reversal $<20 \%$. A tabulated view of the resulting anticipated capacitor 
characteristics is provided below in Table 5.1-1. The resulting effects of a $2 \mathrm{~Hz}$ operation at $40 \%$ reduced operating voltage and minimal voltage reversal did not seem to be an issue. The slight reduction in the operating voltage does provide an estimated increase in the life expectancy by a factor of five. As shown in Table 5.1-1, the anticipated life of $90 \%$ of the capacitors became $1.5 \times 10^{5}$ discharges. This is not adequate for a production-type application, but will provide the needed information for the proof of concept.

Table 5.1-1 Comparison of the manufacturer component under normal life environments and the resulting effects of the exposed parameters.

\begin{tabular}{|l|c|c|}
\hline \multicolumn{1}{|c|}{ Field or parameter } & Manufacture design & $\begin{array}{c}\text { Anticipated level at corrected } \\
\text { operating levels }\end{array}$ \\
\hline \hline Model number & \multicolumn{2}{|c|}{31165} \\
\hline Nominal value & \multicolumn{2}{|c|}{$40 \mathrm{nF}$} \\
\hline Maximum operating voltage & $100 \mathrm{kV}$ in oil & $60 \mathrm{kV}$ at $120 \mathrm{kV}$ operation \\
\hline $\begin{array}{l}\text { Design discharge life for } \\
90 \% \text { survival }\end{array}$ & $3 \times 10^{4}$ & $\begin{array}{c}1.5 \times 10^{5} \text { primarily given by the } \\
\text { reduced operating voltage to } \\
60 \%\end{array}$ \\
\hline Peak Current & $25 \mathrm{kA}$ & $8 \mathrm{kA}$ \\
\hline Operating temperature range $\left({ }^{\circ} \mathrm{C}\right)$ & \multicolumn{2}{|c|}{-10 to 40} \\
\hline
\end{tabular}

\subsection{Screening $3 \mathrm{nF} / 40 \mathrm{kV}$ Capacitors}

Following a similar screening process, 26 ceramic $3 \mathrm{nF} / 40 \mathrm{kV}$ were screened to supply the diode and series switch augmented capacitance. Of the selected population that provided these units, $5 \%$ fallout was observed. The particulars for this screening are to expose $100 \%$ of the units to a $90 \mathrm{kV}$ peak voltage with a rise time of $20 \mathrm{kV} / \mathrm{sec}$ for 12 exposures. To achieve these parameters and maintain an oil-free component, a controlled environment of commercial-grade SF6 was needed. The level of pressure for the test component was six atmospheres. To reduce the quantity of gas, the test chamber was evacuated before it was filled to a nominal 75-psig level. Figure 5.2-1 represents a typical screening profile of these units. In contrast Figure 5.2-2 shows the resulting wave shape during the failure of a component during screening.

As mentioned above, during the screening process, one of the selected components failed. The manufacturer rating of these units was $40 \mathrm{kV}$. As part of the final acceptance of the components at the manufacturer level, units are typically tested to $60 \mathrm{kV}$. During the operational phase, the anticipated stress across these units has a maximum level of $60 \mathrm{kV}$. Other work has shown that these units can successfully be run at these levels under controlled conditions [2]. An elevated screening process has been established to screen out units with internal flaws. 


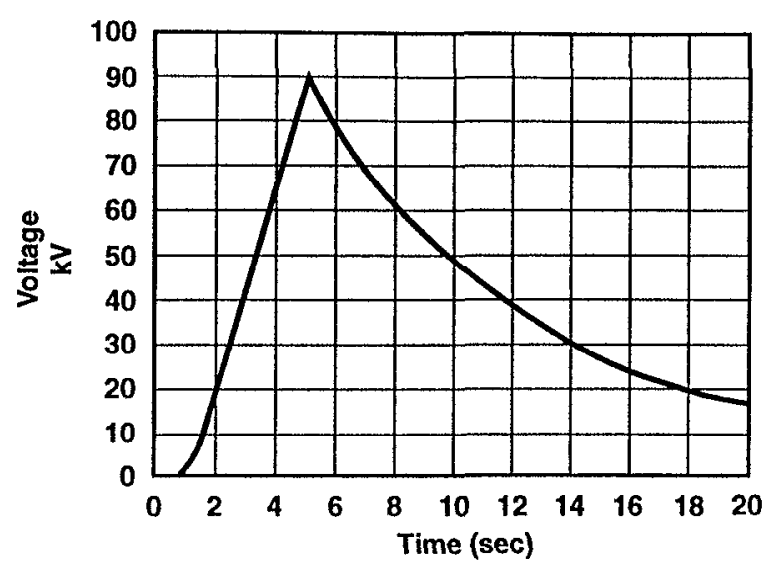

Figure 5.2-1 The above wave shape provides a typical view of the applied voltage to a $3 \mathrm{nF} / 40 \mathrm{kV}$ ceramic capacitor. The peak-measured level is reported to be $90 \mathrm{kV}$, and the rate of rise of the applied voltage is approximately $22 \mathrm{kV} / \mathrm{sec}$. The vertical scale is $10 \mathrm{kV} /$ division and the horizontal scale is $2 \mathrm{sec} /$ division.

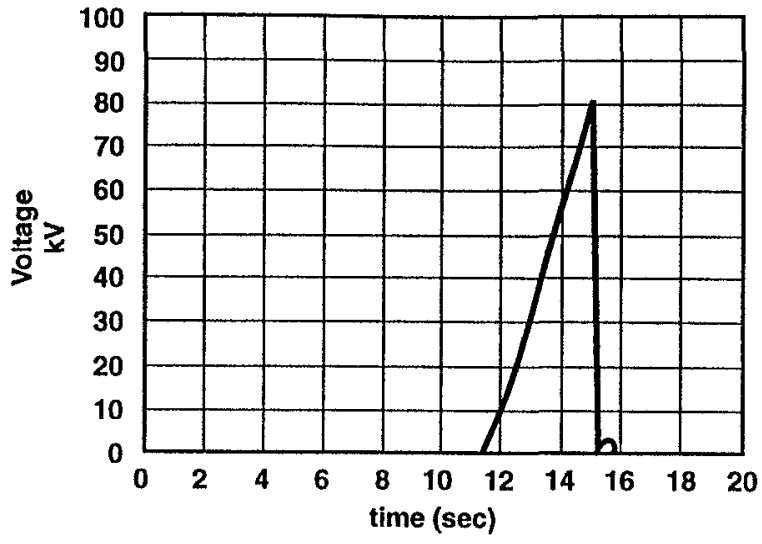

Figure 5.2-2 The above wave shape provides a typical view of the applied voltage to a $3 \mathrm{nF} / 40 \mathrm{kV}$ ceramic capacitor as it failed on the tenth exposure.

\subsection{Screening $100 \mathrm{kV}$ Gas Switches}

The selected switch for this design was a mid-plane, gas-filled Maxwell spark gap. Three units were selected for this use. All three units went through a visual inspection and cleaning. Two units were characterized to ensure that they had similar breakdown characteristics. The third unit was used to characterize the statistical distribution of the static breakdown. The power supply used to evaluate the switch was programmed to provide a typical wave shape (shown in Figure 5.3-1). Allowing constant voltage, the switch pressure was adjusted to obtain the static breakdown levels. The rate of rise of the voltage as shown is a negative going $20-\mathrm{kV} / \mathrm{sec}$ ramp to breakdown. (A represented measured voltage of the breakdown is shown in Figures 5.3-2 through 5.3-7 for different pressure settings.) The curves have been established for the initial operating range up to $100 \mathrm{kV}$. The selected gas for this level of operation was dry air. Elevated voltage above $100 \mathrm{kV}$ will require a gas mixture of SF6 to provide reliable operating characteristics. The voltages were tabulated for analysis and switch comparison. To provide sufficient voltage to intrinsically breakdown the switches at operating pressure, a negative power supply was used. The switch was designed with symmetrical fields in the electrode area and is polarity insensitive. The initial breakdown peak value is the one used to establish the static breakdown relationship. Notice that as the voltage was increased, the switch seemed to close more reliably. Several things occurred as the voltage was increased-all related to the increase in the arc energy. 


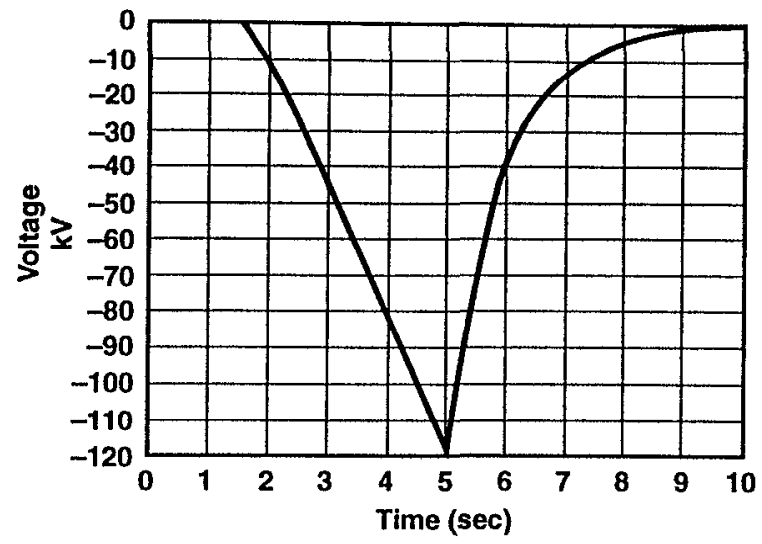

Figure 5.3-1 The above wave shape provides a typical view of the applied voltage to a $100 \mathrm{kV}$ gas-insulated switch.

The rise time of $20 \mathrm{kV} / \mathrm{sec}$ is typical for all the applied voltage for this screening and evaluation. The vertical scale is a $10 \mathrm{kV} /$ division and the horizontal scale is a $1 \mathrm{sec} /$ division.

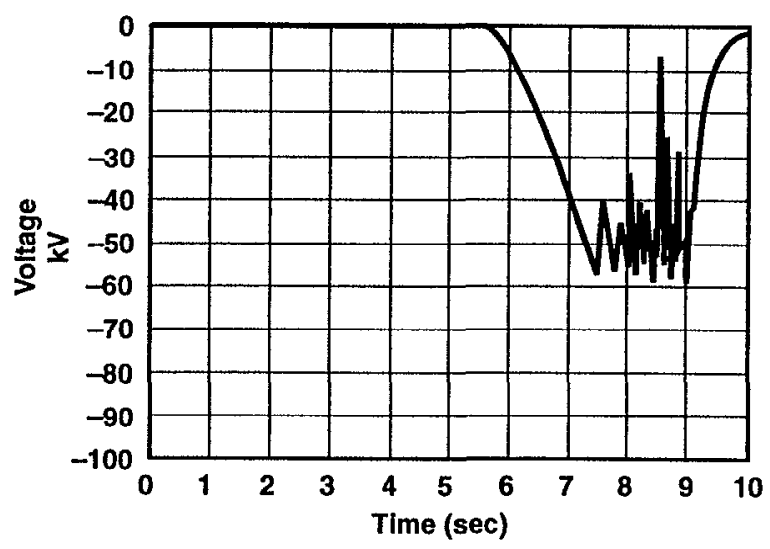

Figure 5.3-3 Static breakdown measurement of a $100 \mathrm{kV}$ switch at 20 psig of dry air. The above wave shape provides a typical view of the applied voltage to a $100 \mathrm{kV}$ gas insulated switch. The rise time of $20 \mathrm{kV} / \mathrm{sec}$ is typical for all the applied voltage for this screening and evaluation. The vertical scale is a $10 \mathrm{kV} /$ division and the horizontal scale is a $1 \mathrm{sec} /$ division.

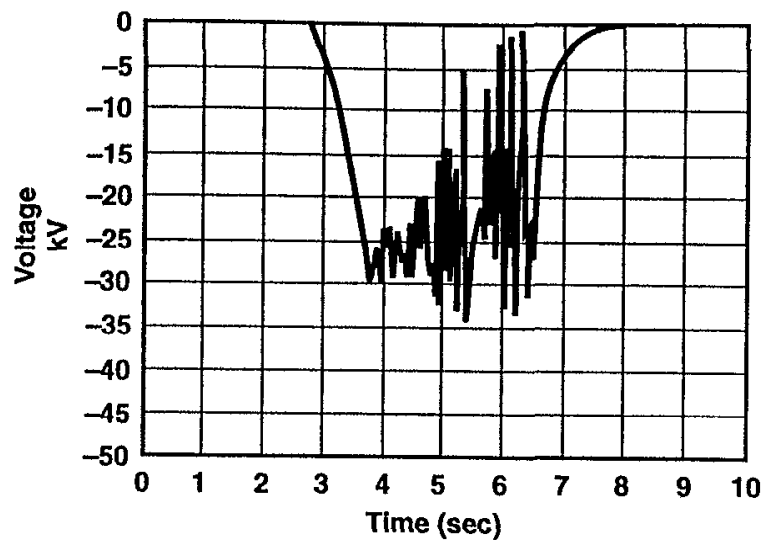

Figure 5.3-2 Static breakdown measurement of a $100 \mathrm{kV}$ switch at 1 atmosphere of dry air. The above wave shape provides a typical view of the applied voltage to a $100 \mathrm{kV}$ gas insulated switch. The rise time of $20 \mathrm{kV} / \mathrm{sec}$ is typical for all the applied voltage for this screening and evaluation. The vertical scale is a $5 \mathrm{kV} /$ division and the horizontal scale is a $1 \mathrm{sec} /$ division.

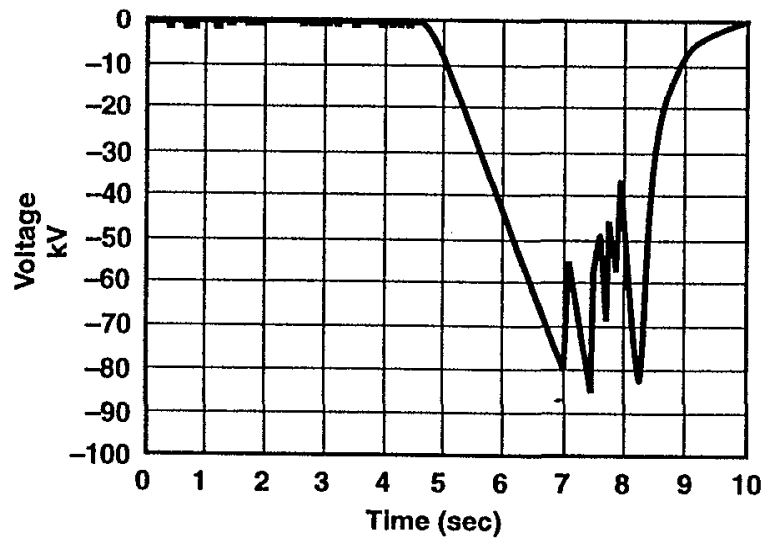

Figure 5.3-4.Static breakdown measurement of a $100 \mathrm{kV}$ switch at 40 psig of dry air. The above wave shape provides a typical view of the applied voltage to a $100 \mathrm{kV}$ gas insulated switch. The rise time of $20 \mathrm{kV} / \mathrm{sec}$ is typical for all the applied voltage for this screening and evaluation. The vertical scale is a and the horizontal scale $10 \mathrm{kV} /$ division is a $1 \mathrm{sec} /$ division. 


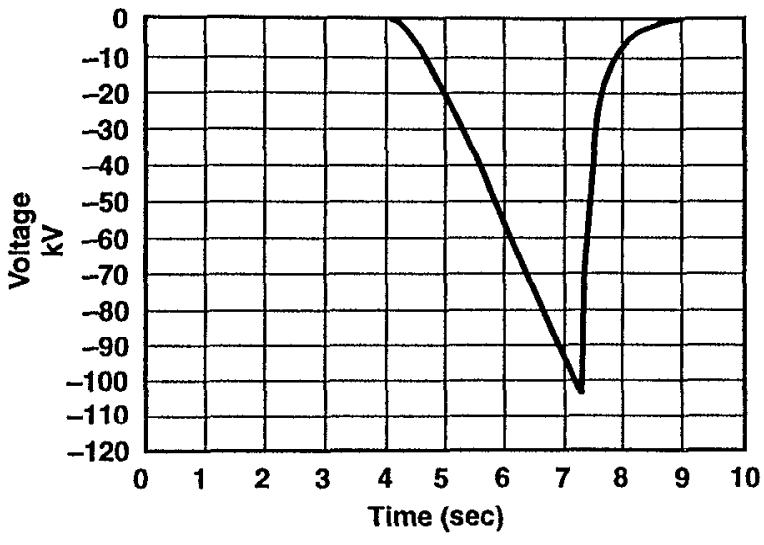

Figure 5.3-5 Static breakdown measurement of a $100 \mathrm{kV}$ switch at 60 psig of dry air. The above wave shape provides a typical view of the applied voltage to a $100 \mathrm{kV}$ gas insulated switch. The rise time of $20 \mathrm{kV} / \mathrm{sec}$ is typical for all the applied voltage for this screening and evaluation. The vertical scale is a $10 \mathrm{kV} /$ division and the horizontal scale is a 1 sec/division.

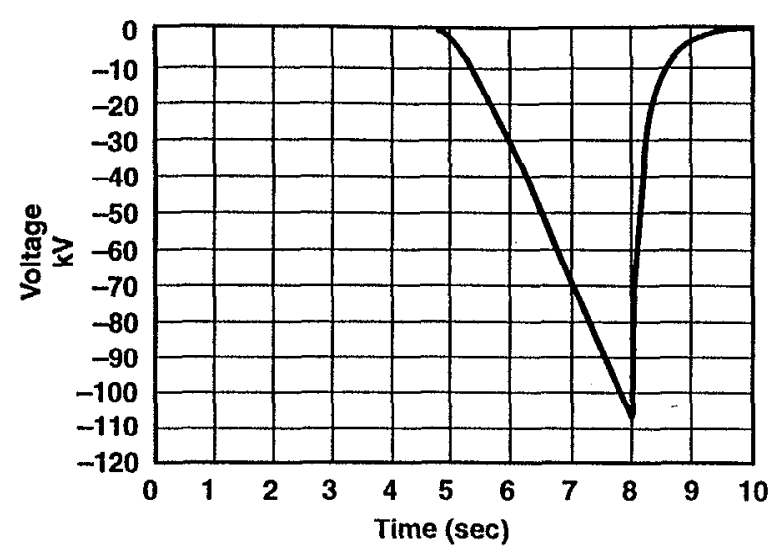

Figure 5.3-6 Static breakdown measurement of a $100 \mathrm{kV}$ switch at 80 psig of dry air. The above wave shape provides a typical view of the applied voltage to a $100 \mathrm{kV}$ gas insulated switch. The rise time of $20 \mathrm{kV} / \mathrm{sec}$ is typical for all the applied voltage for this sereening and evaluation. The vertical scale is a $10 \mathrm{kV} /$ division and the horizontal scale is a $1 \mathrm{sec} /$ division.

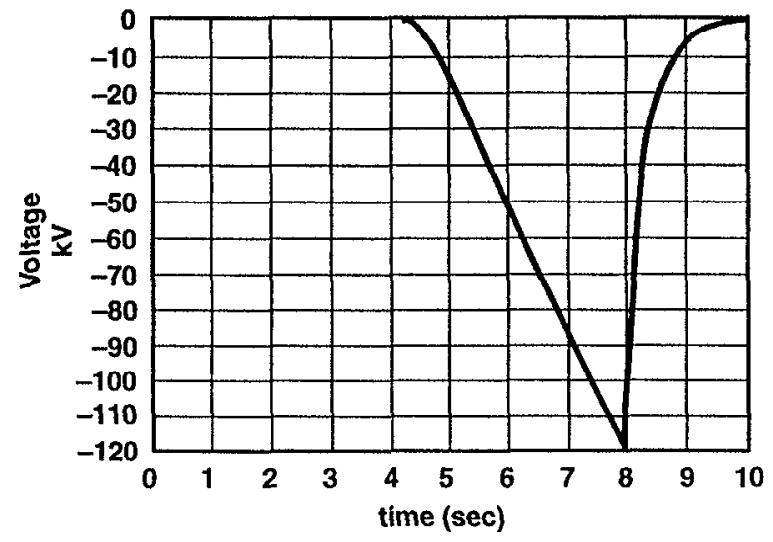

Figure 5.3-7 Static breakdown measurement of a $100 \mathrm{kV}$ switch at 80 psig of dry air when the DUT did not intrinsically breakdown. The above wave shape provides a typical view of the applied voltage to a $100 \mathrm{kV}$ gas insulated switch. The rise time of $20 \mathrm{kV} / \mathrm{sec}$ is typical for all the applied voltage for this screening and evaluation. The vertical scale is a $10 \mathrm{kV} /$ division and the horizontal scale is a 1 sec/division. 


\subsection{Statistical Summary of the Static Breakdown}

As part of establishing the operating curves of gas-filled dielectric switches, a level of static breakdown curves is usually needed. The results of these measurements are generally accepted to have a normal distribution. The graph of this distribution is called a normal curve, or sometimes referred to as bell shape or having a Gaussian distribution. The profile of this curve is shown in Figure 5.4-1.

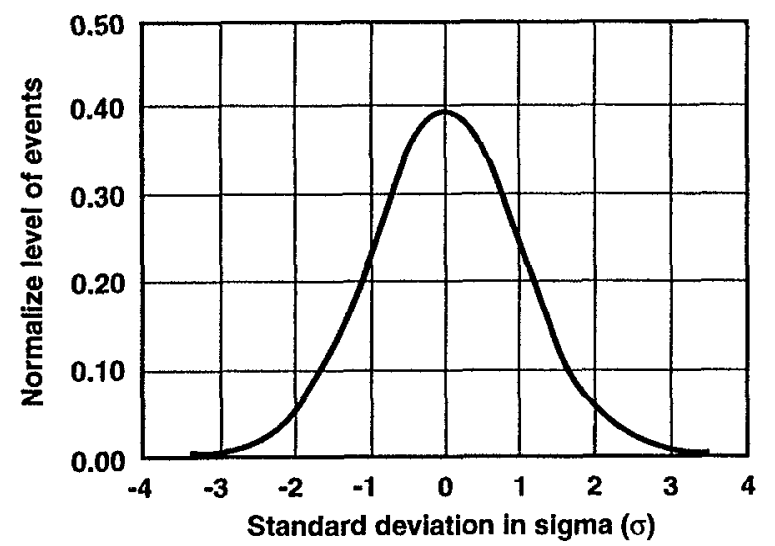

Figure 5.4-1 The above illustration shows a normal distribution of randomly occurring events. This is typical of manufacturing processes and in our case; gas static breakdown levels. The vertical scale represents a normalized level of events at corresponding values of $\sigma$. The horizontal scale is in relative values of $\sigma$ and relates to the average value at " 0. " Remember that the entire population is covered under the above wave shape.

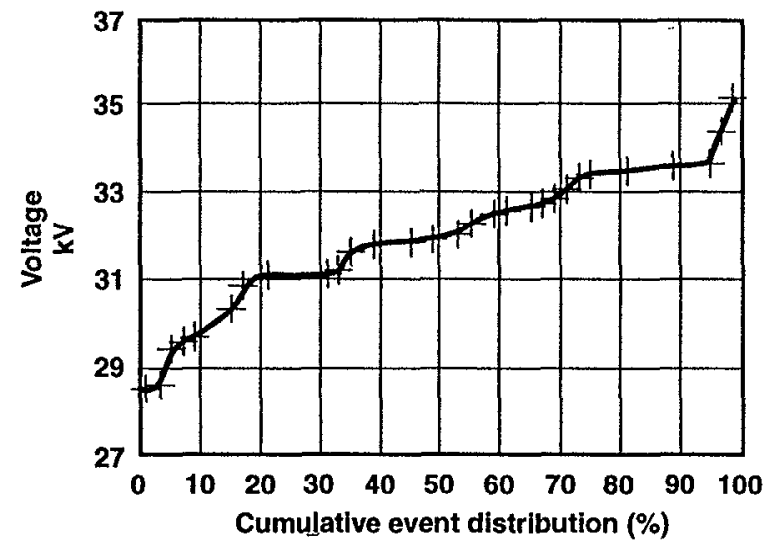

Figure 5.4-2 The cumulative distribution of a series of 50 exposures to a representative $100 \mathrm{kV}$ switch are shown above for a dry air environment of 1 atmosphere. The vertical scale is $2 \mathrm{kV} /$ division and the horizontal scale is 10 percent/division.

Using this curve as a reference, one can easily see why misfires occur. With the horizontal point " 0 " defining the average breakdown voltage, the resulting distribution indicates the probability of a successful breakdown as a function of how well the system repeats. By measuring the distribution one can then predict the probability of misfires or establish an allowable level of prefires/no-fires. An alternative view of this curve is the sigmoid representation of a cumulative distribution as shown in Figure 5.4-2.

The following curves, Figures 5.4-3 through Figure 5.4-5, represent the measured cumulative distributions of static breakdown measurements at different gas pressures. Fifty exposures were used to establish each sigmoid. The steps and roughness of the curves indicated a possible medium change within the housing. Later tests added to this observation, and the addition of added circuitry to the impulser was required to improve system reliability. A table showing the effects of the distribution and relates to these sets of measurements follows. 


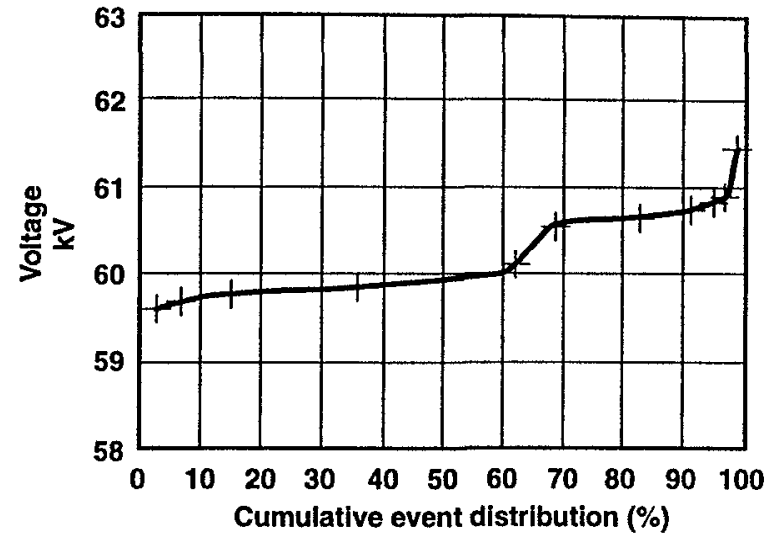

Figure 5.4-3 The cumulative distribution of a series of 50 exposures to a representative $100 \mathrm{kV}$ switch are shown above for a dry air environment of 20 psig. The vertical scale is $1 \mathrm{kV} /$ division and the horizontal scale is 10 percent/division.

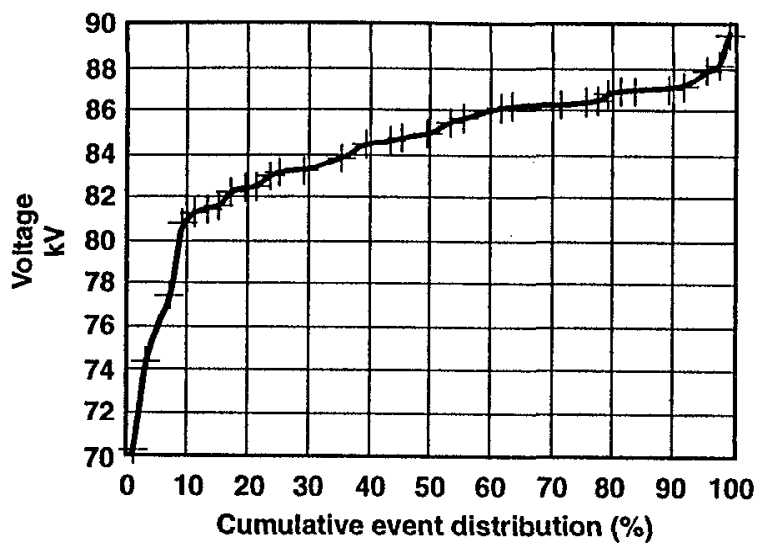

Figure 5.4-4 The cumulative distribution of a series of 50 exposures to a representative $100 \mathrm{kV}$ switch are shown above for a dry air environment of 40 psig. The vertical scale is $2 \mathrm{kV} /$ division and the horizontal scale is 10 percent/division.

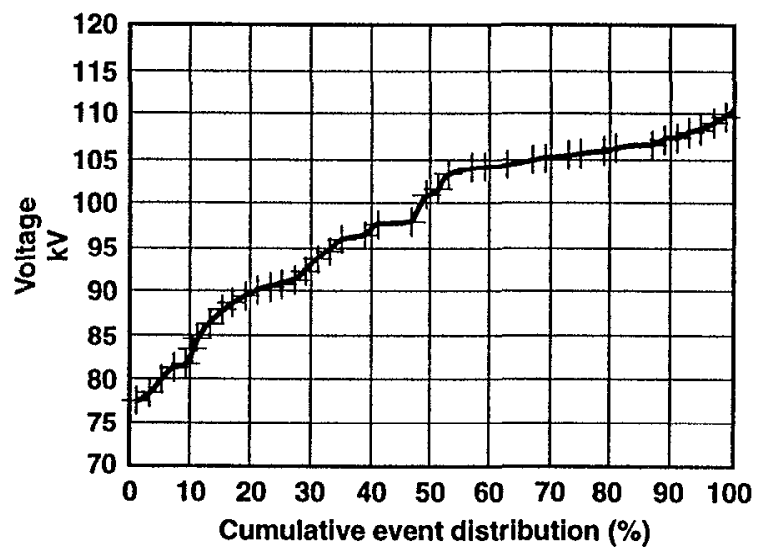

Figure 5.4-5 The cumulative distribution of a series of 50 exposures to a representative $100 \mathrm{kV}$ switch are shown above for a dry air environment of $60 \mathrm{psig}$. The vertical scale is $5 \mathrm{kV} /$ division and the horizontal scale is 10 percent/division.

Using the above information, a summary of the static breakdown characteristics was possible to obtain. This information will be used later to provide operating guidelines. 
Table 5.4-1 Tabulated static breakdown effects of the selected evaluation switch.

\begin{tabular}{|l|c|c|c|c|c|c|c|}
\hline \multicolumn{1}{|c|}{$\begin{array}{c}\text { Gas } \\
\text { Pressure }\end{array}$} & \multicolumn{6}{|c|}{ The value of static breakdown voltage (kV) for the relative values of sigma } \\
\hline & $-3 \sigma$ & $-2 \sigma$ & $-1 \sigma$ & $0 \sigma$ & $1 \sigma$ & $2 \sigma$ & $3 \sigma$ \\
\hline \hline $\begin{array}{l}0 \mathrm{psig} \\
1 \mathrm{~atm}\end{array}$ & 27.70 & 29.13 & 30.56 & 32.00 & 33.43 & 34.86 & 36.29 \\
\hline $\begin{array}{l}20 \mathrm{psig} \\
2.36 \mathrm{~atm}\end{array}$ & 58.84 & 59.29 & 59.73 & 60.17 & 60.61 & 61.05 & 61.49 \\
\hline $\begin{array}{l}40 \mathrm{psig} \\
3.72 \mathrm{~atm}\end{array}$ & 73.62 & 77.18 & 80.73 & 84.28 & 87.83 & 91.38 & 94.93 \\
\hline $\begin{array}{l}60 \mathrm{psig} \\
5.08 \mathrm{~atm}\end{array}$ & 70.85 & 79.88 & 88.91 & 97.94 & 106.97 & 116.00 & 125.03 \\
\hline$\%<\mathrm{n \sigma}$ & 0.13 & 2.28 & 15.87 & 50.00 & 84.13 & 97.72 & 99.87 \\
\hline
\end{tabular}

In Table 5.4-1 shown above, with a switch pressure of $20 \mathrm{psig}$, it would be expected that a representative switch would hold $58.8 \mathrm{kV} .99 .87 \%$ of the time without breakdown. At the same time, given the above distribution, one would expect the switch to hold a voltage greater than $61.5 \mathrm{kV}$ less than $0.13 \%$ of the time. The above static breakdown defines the anticipated prefires and the relationship of operating pressure in dry air relating switch voltage.

These numbers directly relate to the crowbar switch that is in the same family that was tested. Similar construction techniques for the series switch yield reasonably close results. The difference in the series switch has to do with the UV triggering electrode. A more robust switch is required for the crowbar switch because it needs to carry $99 \%$ of the stored energy. Additional circuitry, UV-enhancing the series switch, and heavily triggering the crowbar switch provides similar switch performance for the impulser.

\subsection{Required Diagnostics}

The most difficult part of this effort was to verify a flatness specification of $0.1 \%$ at the 100 $\mathrm{kV}$ operating level. The intent was to use a 20,000-to-1 probe, an 11-bit Tektronix SCD 1000 digitizer and assure that the flatness requirements were met. The need to use the 11-bit digitizers over the lower-end 8-bit units added a nominal factor of ten to the vertical resolution. After the digitizers were obtained it was found that the bit noise levels of the two units available were a nominal six-to-eight discrete measurements steps or a provision for a statement of 0.6 to $1 \%$ possible. This is somewhat disappointing on our part and indicates that Tektronix has not made an increase in the vertical sensitivity relating to bit noise. We are able to provide a typical wave shape to indicate flatness but are not willing at present to state that we can measure the impulse flatness to the level of $0.1 \%$. The vacuum beam quality will be the final snap-shot of the injector performance.

\subsection{Diode Modification}

One of the critical issues in this retrofit is the design iteration to the vacuum diode. Three basic things occurred in this modification. The first was to reduce the rise time of the stress across the diode to the desired level. This was accomplished by increasing its capacitance with symetrically arranged discrete ceramic capacitor surraounding the diode as shown in Figures 7.0-1 and 7.0-2. The second effect was a result of this increased capacitance, which was 
manifested by a decrease in diode impedance as defined by the ratio of the inductance to capacitance. The first two effects had an obvious impact on the electrical performance. The third effect came about in a subtle modification of the electrostatic fields in the diode region.

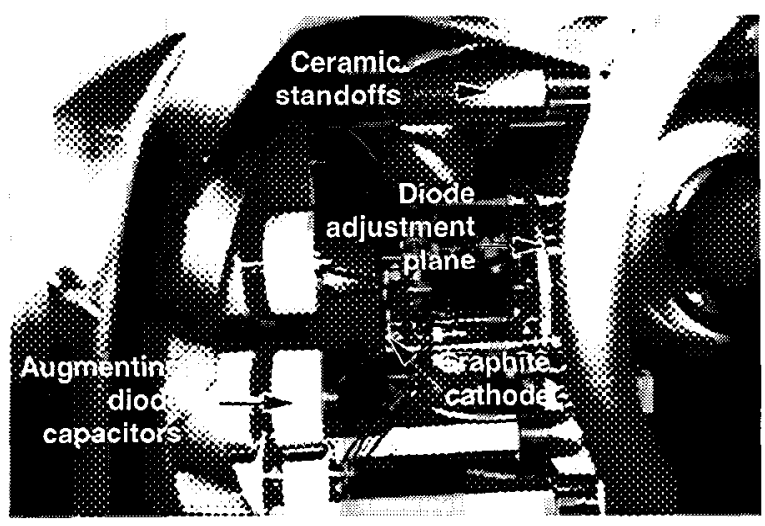

Figure 7.0-1 The modified diode as seen from an open side port. Ceramic capacitors are fitted around the cathode to increase the effective capacitance.

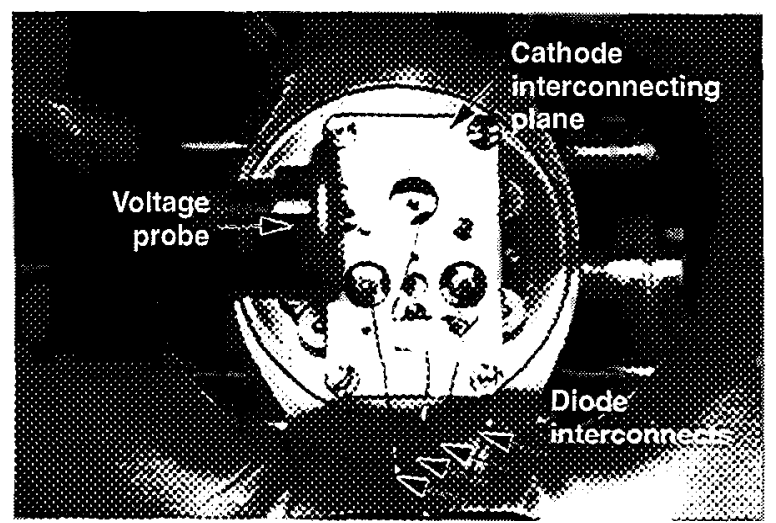

Figure 7.0-2 A rear-view of the diode region. Shown are the interconnections to the diode with bare copper \#12 AWG solid wire. A representative voltage probe is shown attached to the interconnecting plate to measure diode voltage. A partial view of some of the added capacitors is also shown.

After several weeks of operation it was noticed that if the symmetry of the augmenting diode capacitors were changed to a slightly unbalanced configuration, a movement of the impact area of the beam on the anode was observed. This indicates an apparent variation in the beam characteristics and a possible change in beam steering and density. To provide an explanation for this effect, Figures 7.0-3 through 7.0-5 indicate three different capacitor configurations. The initial calculations were made to ensure that the design did not exceed the intrinsic breakdown level of vacuum. The electrostatic equal potential profiles show that the fields had been slightly modified. The initial concern was to ensure that the diode did not preferentially arc to the augmenting capacitors. Figure 7.0-3 shows the initial diode configuration and provides the comparative baseline for proposed modification. A side view of the first proposed capacitor location, shown in Figure 7.0-4, indicated a possible concern and became the reason for this detailed look at optimizing this integrated component. A desired reduction in the fields within the diode region was achieved by lowering the capacitors as shown in Figure 7.0-5. This information became significant in the next level of design. 


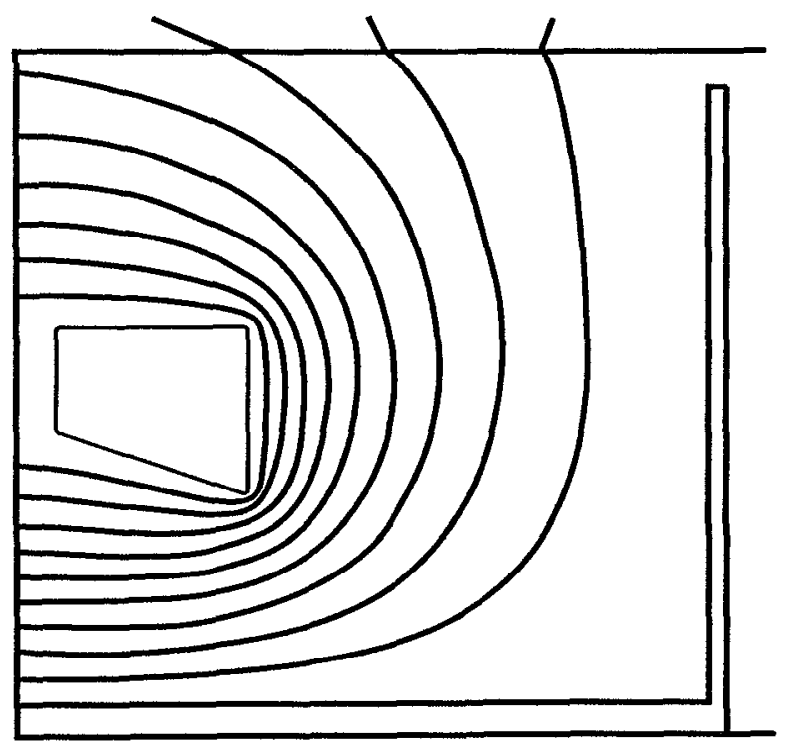

Figure 7.0-3 The electrostatic calculation indicating of the equal potential lines of the diode before modifications.

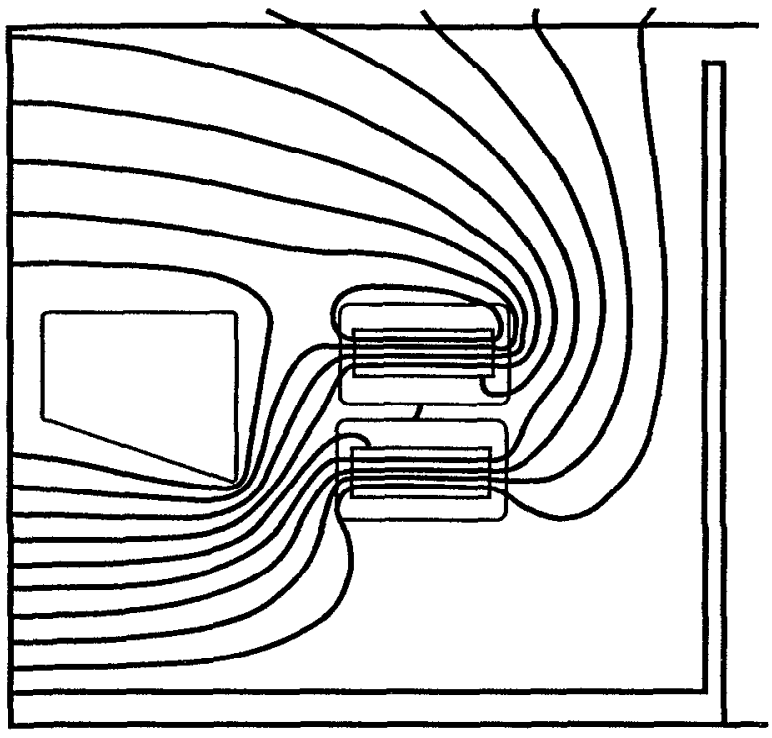

Figure 7.0-4 Illustrated above are calculations indicating an increase in the axial field stress in the diode region.

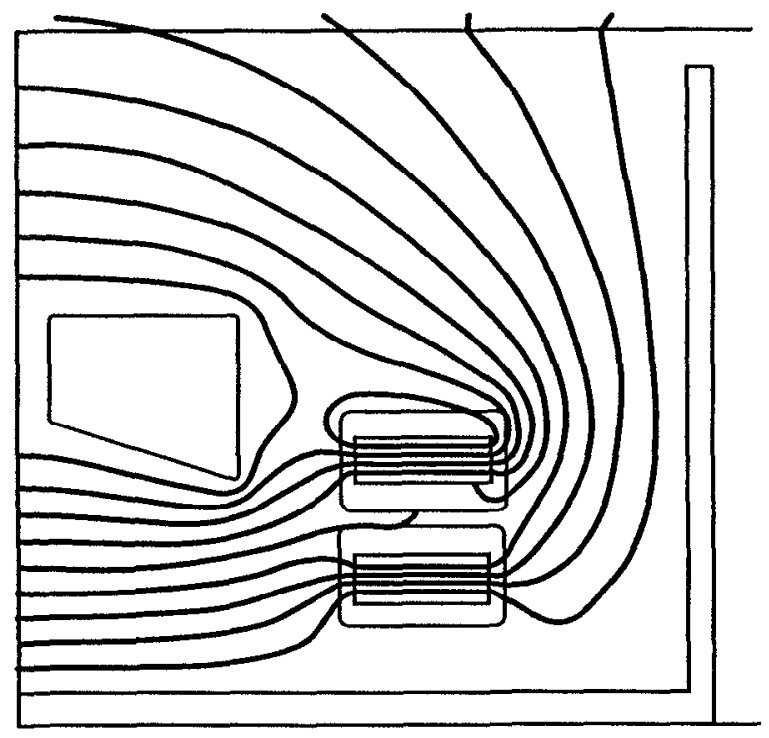

Figure 7.0-5 The result of lowering the capacitors and a slight decrease in relative changing field strength of the diode region.

\subsection{System Interconnection}

The proposed system interconnect is a simple approach however, there are a couple of issues that the operator should be aware of to provide successful system operations. These issues are mentioned in the operating procedures. For clarity and future reference for new operators a few significant points are also provided in this section. 
Because this is an oil system there are additional limits and considerations that need to be taken into consideration to ensure continued operation. Experience is one of the primary teachers for working in this environment and the catalyst for moving away from this requirement. Some of the lessons learned include the following:

- Some plastics become hard after being soaked in oil. Ensure they are where you want them in the initial installation. Keep low-voltage control wiring away from high voltage and diagnostics lines.

- Silicone cable swells in oils. This is usually more of an inconvenience than anything else.

- Oil soaks up water, air, body oils, dust, particles, plastics, and many other contaminates. The oil contaminates typically reduce the oil properties.

- Oil has good insulating electrical characteristics and a good insulator oil has a reasonable dielectric constant and a low conductivity. These two parameters have a hidden agenda that allows the oil to hold charge for a long time. This is sometimes referred to as a dielectric relaxation time constant and can easily be minutes to hours. The result is that when thesc charges assist the electric field as defined by the charge divided by the capacitance, a discharge in the oil will occur when the maximum field stress is exceeded.

- Oil and SF6 are not friendly electrical switching environmënts. SF6 is basically inert by itself. The problem is when the molecule is thermally or electrically decomposed. A joint environment increases the possible recombination byproducts, which appear to be different for each decomposition process, and provides an additional concern during those levels of operation. Venting the exhausted gas is a minimum requirement. This should be standard even for dry air to remove the ozone and other byproducts during the use of that medium. Getting the gas to a submerged switch typically requires the use of a dielectric tube. Poly-flo tubing is not recommended for long term systems. The preferred tubing is Nylo-seal. Oil will leach through the Poly-flo and is therefore not recommended for this reason.

- Most other issues concerning oil are provided in the appropriate Material Safety Data Sheets (MSDS).

\subsection{System Operation}

This section discusses the operation of the impulser. The intent of this robust design is to provide a reasonable tool to conduct experiments. The impulser is not intended to become the focus of the experiment and consume valuable resources better applied to the project development. This point cannot be over emphasized. As mentioned above, some of the selected components do not have the projected life expectancy desired for a final design but they will help establish the specific design requirements for the next generation. To prolong the life of the impulser and minimize the impact of the operation, the following general guidelines should be considered.

\subsection{General Concerns}

Keep a positive pressure on the injector switches when the tank is full of oil. The design of the unit provides a possible operating level to $120 \mathrm{kV}$. To achieve this operating level a mixture of SF6 and $\mathrm{N}$ is required. (The reason for this mixture goes beyond the scope of this report.) The current system will operate to $100 \mathrm{kV}$ without additional controls. A system retrofit is 
recommended to achieve the higher operating levels to include an iterated operating pressure curve. Changes in beam profile may result from a degradation of augmented diode capacitors. To dynamically observe this effect, a vacuum HV-probe is required. Several types of probes are possible and the recommend construction would be resistive instead of capacitive. The voltage probe located in the impulser tank is only representative of the resistively decoupled voltage to the diode. Until a diode probe is installed, beam quality is the best indication of the source quality.

\subsection{Adjusting the Diode Extraction Profile}

As shown in Figure 7.0-2, one sees the voltage probe used to tune the components shaping the diode accelerations voltage. The tuning is done at air and reduced voltage to insure that the diode does not close. It is not necessary to use this specific probe; a lower fidelity unit like a Tektronix P-6015A or equivalent will easily suffice. The adjacent wave shape, Figure 9.2-1 (below), indicates a sample of the diode voltage. The selected width is longer than required and is shown to illustrate the impulse quality.

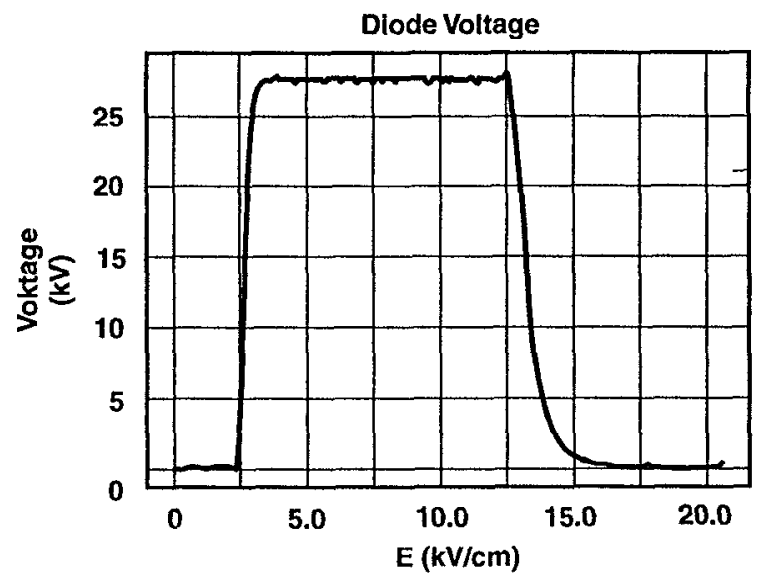

Figure 9.2-1 The above wave shape provides a typical measurement of the voltage across the diode as measured by a Tektronix high-voltage probe.

\subsection{Gas Operating Curve}

The following curve shown in Figure 9.3-1 provides the initial operating parameters for the series and crowbar switch. This curve, as indicated, is for dry air. When operating at voltages higher than $100 \mathrm{kV}$, a mixture of SF6 and nitrogen is recommended. Depending on the selected ratio of these gases, a slightly modified operating profile will be required. The critical issue is that the switches should not be operated above the manufacturer recommended operating pressure level of 100 psig. 


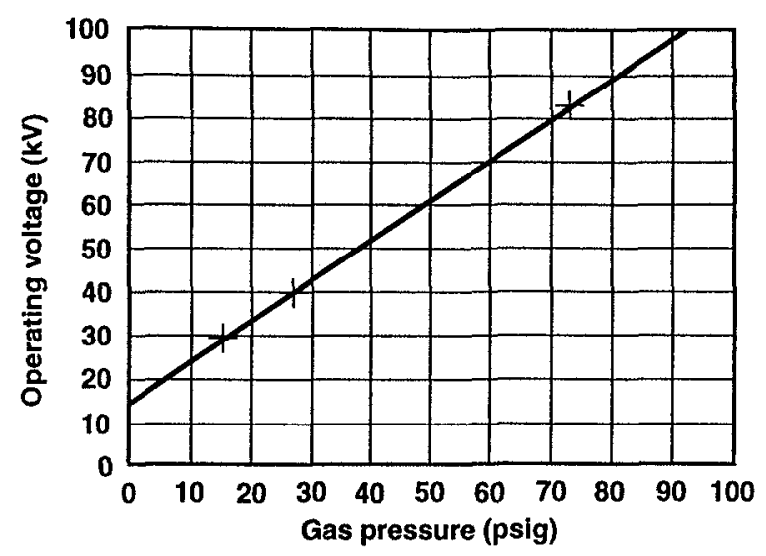

Figure 9.3-1 The operating pressure of dry air as it relates to the charge voltage for both the series and crowbar switches.

\subsection{Fault Protection}

To provide the required impulse wave shape, only a small portion of the stored energy is used for the diode. As a result, a long exponentially decaying pulse is-possible at the diode if the crowbar switch does not operate or the series switch prefires. At some operating point, the diode voltage and impulse duration will be sufficient to cause diode closure. The resulting current for this circuit would be limited by the decoupling resistor (R3). If the crowbar switch docs not operate and the diode collapses, all the stored charge will discharge through the diode. If it is determined that this level of current and charge transfer provides an unacceptable risk to the diode, then some protection can be provided. If the scenario is a series switch prefire, then a fault indicator such as a Rogowski coil or current probe might be considered as an additional command crowbar signal. This signal would initiate the crowbar delay trigger adding the transmission time delay to the width of the pulse.

\subsection{References}

1. Michael J. Wilson and David A. Goerz (1997), "Compact High-Voltage Structures," in The 1997, 11th IEEE International Pulsed Power Conference, Baltimore, MD, June 29-July 2, 1997, pp 1596-1601.

2. Michael J. Wilson, David A. Goerz, and Ron D. Speer, "LCR Bridge Measurements at Elevated Operating Levels," Lawrence Livermore National Laboratory, Livermore, CA, UCRL-ID-125796, December 1997. 


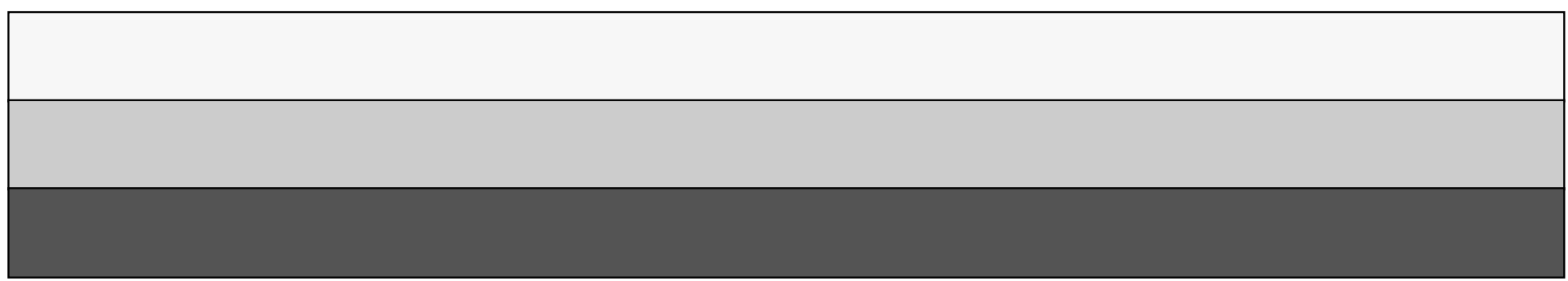

